ORIGINAL PROF-2024

\title{
REFRACTIVE ACCOMMODATIVE ESOTROPIA;
}

\author{
Management and results
}

Dr. Muhammad Safdar lqbal, Dr. Syed Ahmer Hussain, Dr. Zafar ullah Qazi

ABSTRACT... Purpose: To determine the efficacy of all time wear of full cycloplegic correction in the management of refractive accommodative esotropia. Design: Descriptive study using non-probability purposive sampling technique. Setting: Ophthalmology OPD and Department of Nishtar Hospital, Multan. Period: Oct 2009 to Sep 2010. Material and Methods: All children with accommodative esotropia associated with hyperopia were included in the study. The features studied were ocular alignment, association of anisometropia with strabismus and amblyopia, improvement in deviation of squint after amblyopia therapy and full cycloplegic hyperopic correction and regain of binocular single vision and requirement for surgery in patients with accommodative esotropia with hyperopia. Results: Forty four children with refractive accommodative esotropia were identified. Cycloplegic refraction was done for all patients and full cycloplegic correction was given. At presentation 36.4\% of children were amblyopic in either eye and most of them had anisometropic hypermetropia. The esotropia was present in more hypermetropic eye. $63.6 \%$ of the patients became straight with glasses only and another $25 \%$ became straight after amblyopia therapy. Fusion with gross stereopsis was demonstrated in $75 \%$ of patients. Cycloplegic refraction remained stable throughout the follow up period. None of these patients was able to discontinue glasses and maintain alignment. Surgery was required in only $11.4 \%$ of total patients. Conclusions: Most children with refractive accommodative esotropia have an excellent outcome in term of visual acuity, ocular alignment and binocular single vision with the glasses. Full cycloplegic correction and amblyopia therapy resulted in marked reduction in the deviation of squint and improvement in visual acuity of the amblyopic eye as compared with the prevalence at presentation. The degree of hyperopia remains unchanged with poor prospect for discontinuing glasses wear.

Key words: Hyperopia, Esotropia, Amblyopia, Binocular single vision

Article Citation

Iqbal MS, Hussain SA, Qazi Z. Refractive accommodative esotropia; Management and results. Professional Med J 2013;20(2): 301307.

\section{INTRODUCTION}

Esotropia is defined as the manifest inward deviation of the visual axis. The refractive accommodative esotropia is one of the most common forms of childhood strabismus ${ }^{1}$. Two main mechanism contributing to refractive accommodative esotropia are uncorrected hyperopia and insufficient fusional divergence ${ }^{2}$. A third cause may be anisometropia greater than or equal to 1 dioptre especially in patients having lower hyperopia ${ }^{3}$.

Esotropia results when the obligatory accommodative convergence that accompanies reflexive accommodation is insufficiently opposed by fusional divergence ${ }^{4}$. The decreased ability to fuse slightly dissimilar retinal images combined with excessive accommodation causes esotropia ${ }^{5}$. So the accommodative convergence /accommodation ratio is normal in these patients and esotropia is just a physiological response to excessive hyperopia usually between +4.00 and $+7.00 \mathrm{D}^{6}$.

The relation between hyperopia and esotropia is well described. A number of articles have documented increasing hyperopia before the onset of esotropia ${ }^{7,8}$. It is also seen that the amount of hyperopia remains unchanged or changes very slowly with poor prospect for discontinuing glass wear ${ }^{1,9}$.

Raab reported that the majority of his patients with accommodative esotropia continued to require glasses to control their esotropia into their adolescent years10. Repka and coworkers also postulated that accommodative esotropes wearing their full hyperopia correction are less likely to undergo emmetropization ${ }^{11}$. 
The deviation (esotropia) usually presents at about the age of 2.5 years with a range of 6 months to 7 years ${ }^{3}$. Management consists of careful assessment of visual acuity, measurement of deviation, cycloplegic refraction, fundus examination and binocular status.

Treatment consists of correction of full amount of hyperopia as determined under cycloplegic refraction with atropine or cyclopentolate. With full hyperopic correction in place, no accommodative convergence is stimulated, so no deviation results and only a modest amount of accommodation is needed for near fixation $^{12}$. A good number of patients can be managed with the use of proper glasses alone and improvement in visual acuity and binocular single vision can be achieved with early recognition of the disease and timely intervention ${ }^{13}$. All the patients are advised for all time wear of glasses.

Many patients of refractive accommodative esotropia also present with amblyopia or develop amblyopia during follow up. Amblyopia is a developmental defect of spatial visual processing that occurs in the central visual pathways of the eye $e^{14}$. It is the main cause of visual defects in children. It is estimated that amblyopia affect between $1-4 \%$ of the world's population $^{15}$. It develops during the sensitive period of visual maturation, which continue until about 8 years of age ${ }^{16}$. Most cases of amblyopia are associated with strabismus usually esotropia in infancy or early childhood $^{17}$. Recent research also demonstrates that refractive anomalies are the leading cause of amblyopia $^{18}$. Refractive correction and occlusion therapy with patching of sound eye is the mainstay of treatment of amblyopia ${ }^{19}$.

The main benefits of amblyopia therapy include improved stereoptic appreciation and realignment of strabismic eyes with attainment of improved visual acuity. Surgical correction is reserved for patients who fail to regain fusion with glasses or remain significantly undercorrected despite full time glass wear $^{1}$

\section{MATERIAL AND METHODS}

All children with accommodative esotropia associated with hyperopia were included in this descriptive study using non-probability purposive sampling technique. The features studied were ocular alignment, association of anisometropia with strabismus and amblyopia, improvement in deviation of squint after amblyopia therapy \& full cycloplegic hyperopic correction, regain of binocular single vision and requirement for surgery in patients with accommodative esotropia with hyperopia.

\section{RESULTS}

We studied 44 cases of refractive accommodative esotropia. Twenty five (57\%) were male and nineteen (43\%) were female. The age ranged from 02 years to 15 years. Mean age was $7.17 \pm 2.07$ years. Twenty three $(52.3 \%)$ were less than 04 years, while 21 (47.7\%) were of school going age i.e 04-15 years.

In 11 (25\%) patients the esotropia appeared between $1-2$ years of age, in $22(50 \%)$ it was noted between $2-3$ years, while deviation appeared between 3-4 years in $10(22.7 \%)$ of patients. Only 1 (2.3\%) patient was above the age of 05 years. As shown in table-l.

\begin{tabular}{|c|c|c|}
\hline Age (years) & No. of patients & \%age \\
\hline $1-2$ & 11 & 25.0 \\
\hline $2-3$ & 22 & 50.0 \\
\hline $3-4$ & 10 & 22.7 \\
\hline$\geq 5$ & 01 & 02.3 \\
\hline \multicolumn{2}{|c|}{ Table-I. Age at onset of deviation $(\mathrm{n}=\mathbf{4 4})$} \\
\hline
\end{tabular}

We were able to record VA properly in 26 (59\%) while in remaining 18 (41\%) patients VA was estimated by central, steady maintained (CSM) and other methods because these patients were too young for accurate VA measurement. Out of 26 (59\%), nine (34.6\%) had 
VA $6 / 9$ or better at least in one eye on presentation. Ten (38.5\%) had VA between 6/12-6/18 and $7(26.9 \%)$ showed VA less than $6 / 18$ in both eyes. As shown in table-Il.

\begin{tabular}{|l|c|c|}
\hline Visual acuity & No. of patients & \%age \\
\hline $6 / 9$ or better & 09 & 34.6 \\
\hline $6 / 12-6 / 18$ & 10 & 38.5 \\
\hline$<6 / 18$ & 07 & 26.9 \\
\hline
\end{tabular}

Table-II. Visual acuity at presentation

After full cycloplegia with atropine, retinoscopy was done and amount of hypermetropia was determined. Fifteen (34\%) patients were having hypermetropia less than 5D, while 29 (66\%) showed hypermetropia more than 5D. As shown in Fig-1.

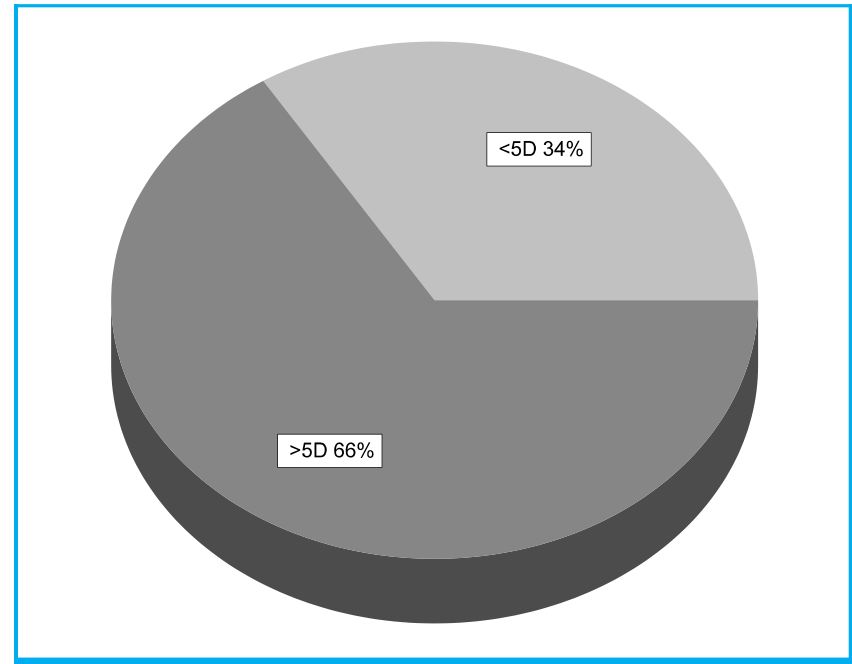

Fig-1. Break up of hypermetropia

Isometropic hypermetropia was present in 28 (63.6\%) patients while 16 (36.4\%) had anisometropic hypermetropia. As shown in Fig-2.

The best corrected VA was taken after full cycloplegic correction i.e. with glasses in place. Sixteen (36.4\%) showed uniocular amblyopia. Most of the patients of uniocular amblyopia presented with uniocular esotropia, and also showed anisometropia. The amblyopia therapy was given by standard method of occlusion of sound eye for most of the waking hours. After amblyopia therapy we were able to improve VA upto $6 / 9$ or better in $8(50 \%)$ patients, while $3(18.7 \%)$ improved VA upto 6/12 -6/18, improvement in VA was estimated in $4(25 \%)$ patients by the observation of alternation of squint. Only $1(6.3 \%)$ improved to $6 / 36$. Most probably it was due to poor compliance.

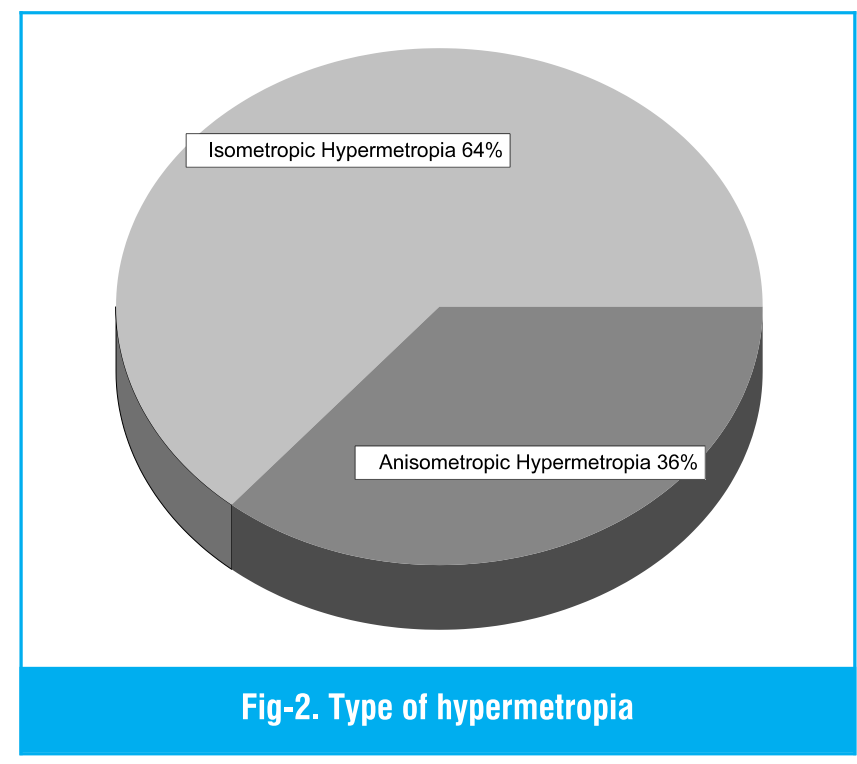

Twenty eight (63.6\%) patients were given full cycloplegic correction and their esotropia was corrected with glasses alone. Another eleven (25\%) patients also became straight with glasses and amblyopia therapy. Five (11.4\%) patients showed very little improvement even after full cycloplegic correction and intensive amblyopia therapy. As shown in table-III.

\begin{tabular}{|l|c|c|}
\hline \multicolumn{1}{|c|}{ Modality of treatment } & $\begin{array}{c}\text { No. of } \\
\text { patients }\end{array}$ & \%age \\
\hline Straight with glasses & 28 & 63.8 \\
\hline $\begin{array}{l}\text { Improved with glasses and } \\
\text { amblyopia therapy after 3 months }\end{array}$ & 11 & 25.0 \\
\hline $\begin{array}{l}\text { Not improved with glasses and } \\
\text { amblyopia therapy after 3 months }\end{array}$ & 05 & 11.4 \\
\hline \multicolumn{2}{|c|}{ Table-III. Management and outcome } \\
\hline
\end{tabular}


The improvement in BSV in the form of fusion and gross stereopsis was noted in 33 (75\%) patients. 7 (15.9\%) patients showed no improvement in BSV. In 4 (9.1\%) patients we were not able to comment on BSV due to poor cooperation. As shown in Fig-3.

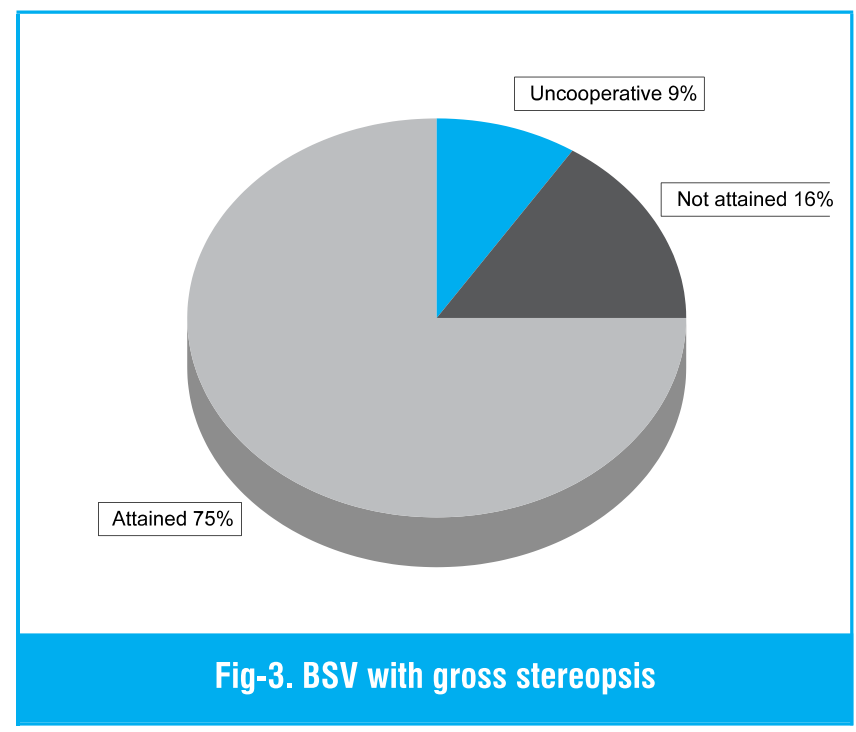

\section{DISCUSSION}

Our study of 44 cases of Refractive accommodative esotropia (RAE) confirms many features, causes and association of the disease. Our results showed that age at presentation of a child with amblyopia, the amount of refractive error (hypermetropia) and anisometropia correlate strongly with the management and outcome of refractive accommodative esotropia. However many patients presented at a later age with amblyopia, uncorrected hypermetropia associated with esotropia and subnormal VA. The male to female ratio was $57: 43$. For the $4(9.1 \%)$ patients, who were above the age of 9 years, presented with dense amblyopia in either eye. These patients showed poor improvement inspite of full cycloplegic correction and amblyopia therapy. It is interesting to note that the deviation was noted much earlier by the parents but they presented very late.

In majority of the patients i.e. $75 \%$ esotropia was noted between 1-3 years of age. In another $22.7 \%$ it was observed before the age of 5 years. Most of the parents knew about the illness of their children much before they consult any ophthalmologist. The reasons for delay were poor socioeconomic conditions and lack of public health education.

All patients with hypermetropia associated with esotropia were included in our study. Twenty 21 $(47.7 \%)$ of the patients showed unilateral squint while it was alternate in $23(52.3 \%)$ of the patients. The esotropia was between $20-40^{\triangle}$ in $36 \%$ and $>40^{\triangle}$ was present in $64 \%$ of the cases. Cycloplegic refraction was done and full cycloplegic correction was given to all patients. $63.6 \%$ of our patients needed glasses only and their deviation was well controlled. In another 25\% ocular alignment was achieved with glasses and after amblyopia therapy. So the majority of our patients i.e. 88.6\% showed improvement regarding VA and ocular alignment with glasses and after amblyopia therapy.

Our findings that glasses are the mainstay of treatment of refractive accommodative esotropia agree with many previous studies'. Von Noorden and Avilla found that only 1 out of 30 showed functional deterioration requiring surgery ${ }^{20}$. Other studies also reflect the major role of glasses to correct hyperopia and amblyopia therapy ${ }^{21}$. Our findings agree with Von Noorden, Avilla and we see that glasses are the mainstay of treatment of patients with refractive accommodative esotropia and surgery is indicated in very few patients i.e. only $11.4 \%$ in our study.

The visual acuity was good in 9 (34.6\%) patients (6/9 or better), between $6 / 12$ to $6 / 18$ in $10(38.5 \%)$ patients and another 7(26.9\%) patients showed VA $<6 / 24$. In remaining $18(41 \%)$ VA could not be recorded properly due to poor cooperation. In these patients vision was estimated by central steady maintained (CSM) method. Lack of alternate fixation and a strong unilateral objection to occlusion were considered diagnostic of amblyopia in the younger age group. The subnormal vision is reported to be less than $6 / 12^{22}$. 
We studied all patients of hypermetropia associated with esotropia. Retinoscopy was done after full cycloplegia and amount of hypermetropia determined. Majority of the patients $29(66 \%)$ had significant hypermetropia i.e above 5D, while it was less than 5D in rest of the $15(34 \%)$ patients.

Our $28(63.6 \%)$ patients showed isometropic hypermetropia while 16 (36.4\%) presented with anisometropic hypermetropia. Among the anisometropic patients, majority i.e. 15 (93.8\%) had a difference of 1-2D between the two eyes. It was also found that in most of the patients, the deviating eye was more hypermetropic.

The relation between hypermetropia and esotropia is well described. A number of articles have documented increasing hypermetropia before the onset of esotropia ${ }^{7,8}$.

This is also emphasised by Abrahamson et.al in a study of 57 cases, where patients with esotropia had a pronounced hypermetropia. They also noted that hypermetropia increases in the deviating eye $e^{22}$. This relation of esotropia to hypermetropia has also been reported by Duke Elder ${ }^{23}$.

In our study many patients presented with amblyopia or develop amblyopia during follow up. It was present in $36.4 \%$ of the patients on initial examination. Moreover most of our patients who presented with amblyopia also had anisometropia, significant or insignificant, and the deviating eye was more hypermetropic.

Amblyopia, a preventable, malady, affects $1-4 \%$ of the world population ${ }^{15}$. Most cases of amblyopia are associated with strabismus usually esotropia in infancy or early childhood ${ }^{17}$.

Recent research also demonstrates that refractive anomalies are the leading cause of amblyopia and among them abnormal level of hyperopia (over +3.5D in one or more meridian) is the most frequent anomaly ${ }^{18}$. Anisometropia is another significant risk factor for developing amblyopia, ${ }^{1,24}$. This is in accordance with our study of 44 cases of refractive accommodative esotropia. Treatment of amblyopic patients was done with standard occlusion therapy of the better eye according to the age i.e one week for every year of age. We decided to terminate occlusion therapy if there was no improvement on three consecutive monthly follow-ups in the presence of compliance and occlusion ${ }^{25}$.

We treated 16 patients of amblyopia, out of 16 , majority i.e $68.7 \%$ showed a maintained improvement in visual acuity to better than 6/12 in amblyopic eye and their esotropia was also well controlled at the last follow up. $25 \%$ patients also showed significant improvement in visual acuity and ocular alignment. While $6.3 \%$ showed poor improvement.

Our results of amblyopia therapy agree with many studies ${ }^{1,19}$. Most amblyopic children benefit visually from amblyopia therapy provided they present early and are compliant with occlusion and glasses.

The functional value of stereopsis in everyday life may be in question ${ }^{26}$, the presence of Binocular single vision (BSV) with fusion undoubtedly contributes to maintain ocular alignment ${ }^{27}$. A very high proportion of our patients $(75 \%)$ showed fusion with demonstrable BSV which compares well with other studies'.

In a study of risk factors for abnormal binocular vision it was concluded that duration of eye misalignment is the primary risk factor for adverse binocular vision outcomes after successful treatment of children with accommodative esotropia ${ }^{28}$. Our $11.4 \%$ patients showed no stereopsis on the last follow up inspite of full cycloplegic correction and amblyopia therapy. All these patients presented very late with suppression and dense amblyopia in either eye. As our results were 
achieved without any surgery, we find no evidence to support Gobin's claim that $50 \%$ of children with RAE may not have BSV and fusion is restored in many of these within one week of surgery ${ }^{29}$. Our findings also contradict with Tomac S who concluded after study of 20 cases of RAE that prognosis is not favourable for restoration of normal stereopsis in these patients ${ }^{30}$.

\section{CONCLUSIONS}

It is concluded from the study that presentation of childhood squint is late in this area although the parents note the disease earlier. Concomitant esotropia associated with hyperopia is the most common type of childhood squint. Hypermetropia is the commonest refractive error responsible for esotropia in children. Anisometropia is a common associated cause of strabismus and amblyopia. A good number of patients can be managed with proper glasses and amblyopia therapy.

Copyright(C) 03 Dec, 2012.

\section{REFERENCES}

1. Mulvihill A, MacCann A, FilitcroftI, Keefe M. Outcome in refractive accommodative esotropia. $\mathrm{Br} \mathrm{J}$ Ophthalmol 2000; 84: 746-9.

2. Liesegang TJ, Skuta GL, Cantor LB. Esodeviations. In: Liesegang TJ, Skuta GL, Cantor LB editors. Pediatric ophthalmology and strabismus. American Academy of Ophthalmology. 2004: 95-6.

3. Diamond GR. Esotropia. In: Yanoff M, Duker JS, editors. Ophthalmology. 2nd ed. Mosby 2004: 583-4.

4. Parks MM, Mitchell PR, Wheeler MB. Concomitant esodeviations. In: Tasman W, Jaeger EA, editors. Duane's clinical ophthalmology. Williams and Wilkins. Philadelphia, Lippincott. 2005; 1: page number (chapter 12).

5. Newell FW. Ocular motility. Ophthalmology principles and concepts, 8th ed. CV Mosby. St. Louis 1996: 4178.

6. Kanski JJ. Strabismus. In: Kanski JJ, editor. Clinical ophthalmology. 5th ed. Oxford: Butterworth-
Heinemann, 2003: 541-2.

7. Abrahamsson M, Fabian G, Sjostrand J. Refraction in children developing convergent or divergent strabismus. Br J Ophthalmol 1992; 76: 723-7.

8. Ingram RM, Gill LE, Goldacre MJ. Emmetropisation and accommodation in hypermetropic children before they show signs of a squint-a preliminary analysis. Bull Soc Belge Ophthalmol 1994; 253: 41-6.

9. Paris V, Andris C, Moutschen A. Benefits of total hypermetropia correction in patients with strabismus. Bull Soc Belge Ophthalmol 1995; 259: 143-53.

10. Raab EL, Spierer A. Persisting accommodative esotropia. Arch Ophthalmol 1986; 104:1777-9.

11. Repka MX, Wellish $\mathrm{K}$, Wisnicki HJ. Changes in the refractive error of 94 spectacles treated patients with acquired accommodative esotropia. Binoc Vis 1989; 4:5-21.

12. Robin $S$. Bringing the management of accommodative esotropianext term into sharp focus. Ame J Ophthalmol 2006; 141: 914-5.

13. Shah MA, Khan S, Muhammad S. Management of childhood squint. J Postgrad Med Inst 2002; 16: 20610.

14. Diamond GR. Amblyopia. In: Yanoff M, Duker JS, editors. Ophthalmology. 2nd ed. Mosby 2004:615-6.

15. Simons K. Pre-school vision screening: rationale, methodology and outcome. Surv Ophthalmol 1996; 41:3-30.

16. Newman DK, Hitchcock A, McCarthy H, Keast-Butler J, Moore AT. Pre-school vision screening: outcome of children referred to the hospital eye services. $\mathrm{Br} J$ Ophthalmol 1996; 80: 1077-82.

17. Woodruff G, Hiscox F, Thompson JR, Smith LK. Factors affecting the outcome of children treated for amblyopia. Eye. 1994; 8: 627-31.

18. Preslen MW, Novak A. Baltimoor vision screening project. Ophthalmol 1996; 103: 105-9.

19. Shah M, Rehman H, Khan MT, Khan MD. Clinical profile 
of amblyopia in Pakistani children age 3 to 14 years. J Coll Phys Surg Pak 2005; 15: 353-7.

20. Von Noorden GK, Avilla CW. Refractive accommodative esotropia? Int Ophthalmol 1992; 16: 45-8.

21. Baker JD, Parks MM. Early onset accommodative esotropia. Eye 1980; 90:11-8.

22. Abrahamsson M, Fabian G, Sjostrand-J. Refracting changes in children developing convergent or divergent strabismus. Br J Ophthalmol 1992; 76: 7237.

23. Duke Elder S, Wybar K. Abnormal ocular motility. In: Duke Elder S, Wybar K, eds. Ocular motility and strabismus. "System of Ophthalmology". Vol VI. London: Kimpton 1973: 577-641.

24. Sharma P. Role of occlusion in amblyopia. The Strabiscope (India), 1995; 2: 15-6.
25. Moseley RM, Fielder AR. Occlusion therapy for childhood amblyopia. Current concepts in treatment evaluation. In: Vital-Durand F, Atkinson J, Braddick OJ editors. Infant vision. Oxford University Press, 1996: 383-99.

26. Fielder AR, Moseley MJ. Does stereopsis matter in human? Eye 1996; 109: 233-8

27. Wilson ME, Bluestein EC, Parks MM. Binocularity in accommodative esotropia. J Pediatr Ophthalmol Strabismus 1993; 30: 233-6.

28. Wick B. Accommodative esotropia: efficacy of therapy. J Am Optom Assoc 1987; 58: 562-6.

29. Gobin MH. Binocular vision after surgical correction of accommodative esotropia. Bull Mem Soc Fractures Ophthalmol 1985; 96: 95-7.

30. Tomac S. Binocularity in refractive accommodative esotropia. J Pediatr Ophthalmol Strabismus 2002; 39: 226-30.

\section{AUTHOR(S):}

1. DR. MUHAMMAD SAFDAR IQBAL Assistant Professor Department of Ophthalmology Nishtar Hospital, Multan

2. DR. SYED AHMER HUSSAIN

Assistant Professor Department of Ophthalmology Nishtar Hospital, Multan

3. DR. ZAFAR ULLAH QAZI

Associate Professor Department of Ophthalmology Nishtar Hospital, Multan
Correspondence Address:

Dr. Muhammad Safdar lqbal

Assistant Professor Department of Ophthalmology

Nishtar Hospital, Multan

shaukat372000@gmail.com

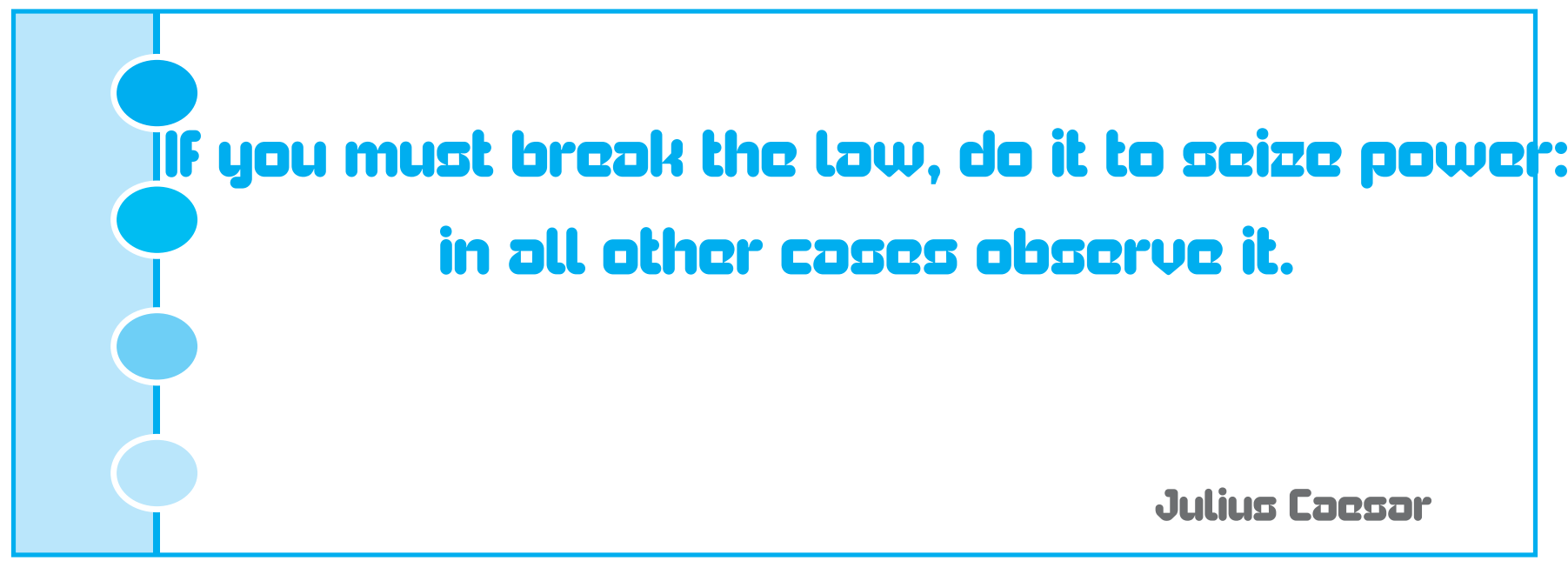

